www.jmscr.igmpublication.org

Impact Factor 3.79

Index Copernicus Value: 5.88

ISSN (e)-2347-176x ISSN (p) 2455-0450

crossref DOI: _http://dx.doi.org/10.18535/jmscr/v4i02.56

Journal Of Medical Science And Clinical Research

\title{
The significance of CD1d expression in diagnosis of chronic lymphocytic leukemia and its value as a prognostic marker
}

\section{Authors \\ Dahlia Ahmed El Sewefy ${ }^{1}$, Gehan Mostafa Hamed ${ }^{2}$}

Clinical Pathology Department, Faculty of Medicine, Ain Shams University

${ }^{1}$ MD Clinical Pathology, Professor of Clinical Pathology, Clinical Pathology Department, Hematology Unit,

Faculty of Medicine, Ain Shams University, Cairo, Egypt

${ }^{2}$ MD Clinical Pathology, Lecturer of Clinical Pathology, Clinical Pathology Department, Hematology Unit,

Faculty of Medicine, Ain Shams University, Cairo, Egypt

Corresponding Author/ Reprints

Gehan Mostafa Hamed

67 El Nasr St, Sheraton Heliopolis, Cairo, Egypt

Email: gehanzeina@yahoo.com,0020201224954542

\begin{abstract}
Back ground Chronic lymphocytic leukemia (CLL) is the most common type of leukemia in adults, its clinical course is highly heterogeneous. Proper diagnosis and discrimination of CLL from other B-chronic lymphoproliferative disorders (B-CLPDs), as well as prediction of disease outcome are very helpful in patient management and therapeutic decision-making.

Methods CDId expression was measured in 43 newly diagnosed B-CLPDs patients including: 20 CLL, 10 $M C L$ and 13 other B-CLPDs, and 10 age- and sex-matched controls.

Results Median CDId \% expression in CLL patients (16\% [IQR; 9-31]) was significantly lower than normal controls and B-CLPDs ( $<<0.001)$. CDId cut off value $<38 \%$ can differentiate CLL from MCL and other B-CLPDs with high sensitivity and specificity. CDld expression was significantly higher in CLL patients with advanced Rai stages ( $p<0.001)$, high CD38 expression (31 [20-35] versus, 9 [7.5=12]; p<0.001), poor cytogenetic abnormalities compared with CLL patients without poor cytogenetic abnormalities (15 [8.2 - 32 ] versus, 7.3 [2 - 16.6]; $p=0.038$ ).

Conclusion CDId is a useful diagnostic marker that can differentiate CLL from MCL and other B-CLPDs. Higher CDld expression in CLL is associated with poor prognosis and can define a subpopulation with more aggressive disease.
\end{abstract}

Key words CDId, CLL, Diagnosis, prognostic marker.

\section{Introduction}

B-Cell chronic lymphoproliferative disorders (BCLPDs) with leukemic manifestations comprise a heterogeneous group of diseases arising from the clonal expansion of mature B lymphocytes at diverse stages of differentiation. The accurate discrimination of each separate B-CLPD entity is of paramount importance because the prognosis and treatment differ widely for the different types $[1,2]$. 
Chronic lymphocytic leukemia (CLL) is the most common type of leukemia in adults ${ }^{[3]}$. Flow cytometric scoring and pattern recognition recommendations have been developed to diagnose and distinguish CLL from other BCLPDs according to the World Health Organization classification (WHO) ${ }^{[4]}$. Nevertheless, the biologic variability of B-CLPDs, the paucity of disease-specific markers and/or immunophenotypic patterns, and the lack of standardized panels and analysis strategies compromise the diagnostic efficiency of immunophenotyping ${ }^{[5]}$. Accordingly, although in most cases of typical CLL and MCL the immunophenotypic diagnosis is straightforward, an appreciable proportion of CLL cases fails to be identified with the classical scoring system, resulting in misclassification ${ }^{[6]}$, while on the other hand, many otherwise typical MCL cases may, in fact, represent CLL ${ }^{[7]}$.

Chronic lymphocytic leukemia is an incurable disease, yet the clinical course is highly heterogeneous; some patients dying from their disease within months, while others have a normal life expectancy. Predicting the disease outcome is therefore very helpful in patient management and therapeutic decision-making ${ }^{[8]}$. At diagnosis, the determination of the correct type of B cell disease associated with a precise outcome prediction currently depends on the interpretation of flow cytometry, cytogenetic and molecular analyses by the corresponding experts, i.e. hematologists, cytogeneticists and pathologists. These methods are costly, and labor- and time-intensive. Cheaper, objective and rapid techniques are therefore warranted $^{[9]}$.

CD1d is a non-polymorphic HLA class I-like, B2microglobulin (B2M) associated glycoprotein that present lipids and glycolipids at the cell surface for recognition by immunoregulatory $\mathrm{T}$ lymphocytes, the natural killer (NK) cells ${ }^{[10]}$. CD1d is expressed widely in normal hematopoietic and nonhematopoietic cells such as thymocytes, monocytes, macrophages, primitive hematopoietic stem cells, keratinocytes, and hepatocytes, whereas normal peripheral blood B cells exhibit constitutive expression of CD1d. As regards hematopoietic malignancies, myeloid and lymphoid acute leukemias variably express CD1d [11]. Nevertheless, CD1d expression has not been widely studied in B-CLPDs. This work aims to evaluate the diagnostic usefulness of CD1d in differentiation of CLL from other B-CLPD, as well as, assessment of its prognostic value in CLL.

\section{Subject and methods}

This study was carried out on 43 newly diagnosed patients with chronic lymphoproliferative neoplasms, attending the Hematology/Oncology Unit, Ain Shams University Hospitals. Another 10 age- and sex- matched healthy adults were enrolled as a control. Informed consent was obtained from patients and controls before enrollment. This study was approved by the ethical committee of Ain Shams University.

All the patients were subjected to full clinical history taking, laying stress on history of fever, weight loss and night sweats. Thorough clinical examination, laying stress on the presence of lymphadenopathy, splenomegaly and hepatomegaly. Abdominal ultrasonography for spleen, liver and lymph node enlargement. Diagnostic workup for B-CLPDs included complete blood counts (CBC) on Coulter LH 750 cell counter (Coulter, Electronics, Hialeah, FL, USA). Bone marrow (BM) aspiration with examination of Leishman stained peripheral blood (PB) and BM smears. Flow cytometric Immunophenotyping was performed on $\mathrm{PB}$ or $\mathrm{BM}$ samples using a standard panel of monoclonal antibodies (MoAb) (CD19, CD5, CD23, FMC7, CD79b, CD38, CD25, CD103, CD 123 and surface immunoglobulins Kappa and Lambda light chains) on Coulter Epics XL 3-color flow cytometer (Coulter, Electronics, Hialeah, FL, USA). Fluorescence in situ hybridization (FISH) for detection of $\mathrm{t}(11 ; 14)$ for all MCL cases, and detection of cytogenetic abnormalities in CLL (deletions of $11 \mathrm{q}$, and $17 \mathrm{p}$ ). Diagnosis was 
established in all cases on the basis of clinical, morphologic, immunophenotypic, Cytogenetic and histologic criteria, according to the WHO classification $^{[4]}$.

\section{Sampling}

Blood and BM aspiration samples were collected under complete aseptic conditions on ethylene diamine tetra-acetic acid, potassium salt $\left(\mathrm{K}_{2}-\right.$ EDTA) $(1.2 \mathrm{mg} / \mathrm{mL})$ for CBC and IPT. For FISH examination $1 \mathrm{~mL}$ of $\mathrm{BM}$ aspirate was collected in tubes coated with lithium heparin.

\section{CD1d expression}

Bone marrow and/or peripheral blood samples anti coagulated with EDTA were kept at ambient room temperature and processed within 24 hours of collection using standard three colour staining and red cell lysis flow cytometric technique, samples were diluted 1:1 with phosphate buffer saline (PBS), pH 7.4 (Sigma Chemicals, St Louis), the final cell count suspension was adjusted between 5 and $10 \times 10^{9} / \mathrm{L}$. For each sample two tubes were prepared one for the test and the other for the isoptypic control, $50 \mu \mathrm{L}$ of diluted sample was delivered in each tube, $5 \mu \mathrm{L}$ of phycoerythrin (PE) labeled CD1d (CD1d kit, Abcam, San Francisco, CA, USA) monoclonal antibody was added to test tube and $5 \mu \mathrm{L}$ of isotypic match control was added to the control tube. Mixing by vortex was done, followed by incubation for 15 minutes at room temperature in the dark. Then the cells were washed with $2 \mathrm{~mL}$ PBS (centrifuged at $3000 \mathrm{rpm}$ for $5 \mathrm{~min}$ ), supernatant was discarded, followed by red cell lysis using $1.5 \mathrm{~mL}$ of $\mathrm{NH}_{4} \mathrm{Cl}$ solution buffered with $\mathrm{KHCO}_{3}$ at $\mathrm{pH} 7.2$ for 3 minutes at room temperature in the dark. Centrifugation was carried out; supernatant was discarded, followed by addition of $1 \mathrm{~mL}$ PBS to cell pellet, and mixing by vortex. Analysis was performed on Coulter Epix XL flow cytometer (Coulter Corporation). If the tubes were not processed within 2 hours, $1 \mathrm{~mL}$ of fixative ( $4 \mathrm{~g}$ paraformaldhyde in $100 \mathrm{~mL}$ PBS with $0.1 \% \mathrm{Na}$ azide, $\mathrm{pH} 7.4$ ) was added and the tubes were kept at $4^{\circ} \mathrm{C}$ until analyzed within 24 hours. A minimum of 5000 events were studied. B cells with CD1d expression were analyzed within gated CD19 positive B lymphocytes

\section{Cytogenetic Analysis}

Cytogenetic analysis by FISH technique using fluorophore labeled locus specific identifier (LSI) dual coloured probes (Vysis, Abbot, molecular diagnostics, USA): LSI TP53 Spectrum Orange/CEP 17 Spectrum Green Probe and LSI ATM Spectrum Orange/CEP 11 Spectrum Green Probe were applied on $\mathrm{BM}$ or $\mathrm{PB}$ samples for detection of p53 (17p13) deletions and ATM (11q22) deletions, respectively. Slides were prepared from material fixed in methanol-acetic acid. All probes were set up separately on different slides for each patient. Hybridization and detection of hybridization signals were performed according to the manufacturer's protocols. For each probe, at least 100 interphase cells were evaluated using the Chromoscan (CytoVision 2.7, Santa Clara, California, USA) in order to detect the target abnormalities. Images of FISH were captured through the program Mac Probe 4.4 of Power Gene System (Applied Imaging Corporation, USA). Two healthy volunteers were used as controls to check the signals of the probes used.

\section{Study group}

Patients were classified into CLL and other BCLPDs subgroups according to WHO classification of B-cell neoplasms ${ }^{[4]}$.

CLL group included 20 patients; 16 males and 4 females with a male to female ratio of $4: 1$. Their ages ranged from 44 to 75 years with a mean age of $59 \pm 9$ years. Clinical stage was determined according to the Rai classification system [12]; stage 0 ( 9 cases), stage I-II (6 cases) and stage IIIIV (5 cases).

MCL group included 10 patients; 6 males and 4 females with a male to female ratio of 1.5:1. Their ages ranged from 35 to 83 years with a mean age of $62 \pm 13$ years.

B-CLPDs group included 13 patients; 8 males and 5 females with a male to female ratio of $1.6: 1$. 
Their ages ranged from 45 to 75 years with a mean age of $58 \pm 9$ years. According to morphologic, immunophenotypic criteria and tissue biopsies they were classified into 4 cases HCL including one case HCL-v, 5 cases SMZL including 2 cases SMZL with villious lymphocyte and 4 cases FL. Clinical and laboratory data of all studied patients are listed in Table 1

\section{Statistical Analysis}

Data were analyzed using statistical program for Social Science (SPSS) version 18 IBM compatible PC. Quantitative data were described in the form of number and percentage, range, mean \pm standard deviation (SD). Qualitative data were described as frequency, and percentage. Student $t$, MannWhitney $U$, Chi square $x^{2}$ were used for intergroup comparison. Pearson's correlation $(r)$ was used for correlating data and Spearman's rank correlation coefficient (rs) was used for correlating between data when one or more is skewed. Receiver operating characteristic (ROC) curve was used to find out the overall diagnostic value of CD1d and to determine the best cut-off value with detection of sensitivity and specificity at this cut-off value. A $p$ value $<0.05$ was considered significant.

\section{Results}

\section{CD1d expression in all studied B-CLPDs and controls}

CD1d was positively expressed on $100 \%$ of normal polyclonal B-lymphocytes of the control group with a median of $82.6 \%$ (IQR; 71.4-97.9), and median mean fluorescence intensity (MFI) of 3.35 (IQR; 2.2- 6.5). Median CD1d \% expression among CLL patients was $16 \%$ (IQR; 9-31) and MFI was 1.19 (IQR; 1.05-1.3) which was significantly lower than the controls $(\mathrm{p}<0.0001)$ (Table 2).

Regarding $\mathrm{CD}^{+}$B-CLPDs, CD1d positivity was detected in $90 \%$ of MCL with median CD1d \% expression of $76.5 \%$ (IQR; 52-89) and MFI of 2.09 (IQR; 0.91-3.64). CD1d expression was significantly lower in CLL compared with MCL $(\mathrm{p}<0.001)$. No significant difference was found as regards MFI ( $p>0.301)$ (Table1 and figure 1).

The median percentage of CD1d expression in CD5 B-CLPDs was 74.3\% (IQR; 67\%-85\%) and MFI was 1.58 (IQR; 1.14-1.93). Median CD1d \% expression was significantly lower in CLL compared with $\mathrm{CD}^{-}$B-CLPDs $(\mathrm{p}<0.001)$, while no significant difference was found as regards MFI ( $p>0.058)$ (Table1)

Using ROC curve analysis to detect the diagnostic significance of CD1d among CD5+ B-CLPDs, revealed that $\mathrm{CD} 1 \mathrm{~d}$ levels $\leq 38 \%$ is a significant diagnostic marker that can differentiate between CLL and MCL cases, with $90 \%$ specificity, $100 \%$ sensitivity, 95.2\% positive predictive value (PPV) and $100 \%$ negative predictive value (NPP) (figure 2A). Likewise, CD1d expression $<38 \%$ can differentiate between CLL and CD5 B-CLPDs with $100 \%$ sensitivity, specificity, NPV and PPV (figure 2B). The high diagnostic accuracy of CD1d was further illustrated by the fact that the area under the curve was 0.915 when measured in CD5+ case, and was 1.00 when measured in CD5 negative B-CLPDs patients, indicating an almost ideal diagnostic test.

No significant difference was found between MCL and other B-CLPD groups as regards their median CD1d \% expression (76.5\% [IQR; 52-89] for MCL versus 74.3\% [IQR; 67\%-85\%] for other B-CLPDs, $\mathrm{p}=0.829)$, or their MFI (2.09 [0.913.64] for MCL versus 1.58 [1.14-1.93] for other B-CLPDs, $\mathrm{p}=0.335$ ).

\section{CD1d expression in different prognostic CLL subgroups}

As shown in Table 2, median CD1d\% expression was low among stage 0 CLL patients (1.32 [0.54 2.5]) compared with both stage I-II and stage IIIIV CLL patients (8.9 [3.9-16.2 ] versus, 14.6 [9.7-32 ]; $\mathrm{p}<0.001$ ) (figure $3 \mathrm{~A}$ ).

CD38 positive CLL patients had significantly higher median CD1d \% compared with CD38 negative CLL patients (31 [20-35] versus, 9 [7.5=12]; $\mathrm{p}<0.001$ ) (figure 3B). 
The poor prognostic cytogenetic aberrations, $17 \mathrm{p}$ del and 11q del were detected in $40 \%$ of studied CLL patients, median CD1d\% expression and IQR were significantly higher among patients with poor cytogenetic aberrations compared with CLL patients without those cytogenetic abnormalities (15 [8.2 - 32 ] versus, 7.3 [2 - 16.6]; $\mathrm{p}=0.038)$ (figure 3C).

Table1. Clinical and laboratory data of all studied patients with B-CLPDs

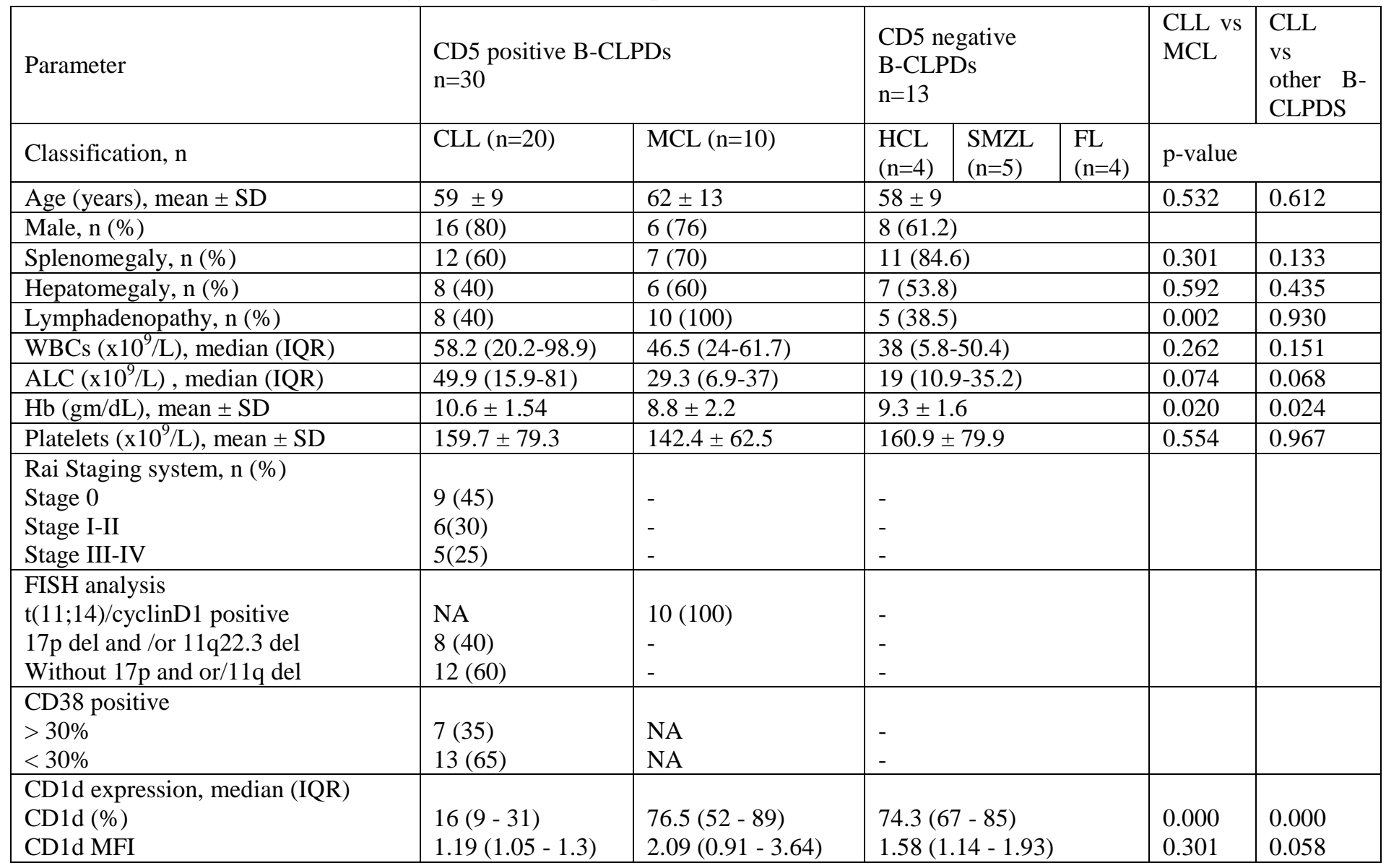

WBCs: white blood cell count, ALC: absolute lymphocytic count, Hb: hemoglobin, FISH: fluorescence in situ hybridization, del: deletion, MFI: mean fluorescence intensity, B-CLPDs: B chronic lymphoproliferative disorders, CLL: chronic lymphocytic leukemia, MCL: mantel cell leukemia, HCL: hairy cell leukemia, SMZL: splenic mantle zone lymphoma, FL: follicular lymphoma.

Table 2. CD1d expression among the controls and CLL subgroups

\begin{tabular}{|l|l|l|}
\hline Variable & Median CD1d\% (IQR) & - value \\
\hline Control group & $82.6(71.4-97.9)$ & 0.000 \\
\hline CLL & $16(9-31)$ & \\
\hline Rai - Staging & $1.32(0.54-2.5)$ & 0.000 \\
Stage 0 & $8.9(3.9-16.2)$ & \\
Stage I-II & $14.6(9.7-32)$ & \\
Stage III-IV & $31(20-35)$ & 0.000 \\
\hline CD38 expression & $9(7.5-12)$ & \\
positive CD38 & $15(8.2-32)$ & 0.038 \\
negative CD38 & $7.3(2-16.6)$ & \\
\hline FISH analysis & Poor prognostic (17p del and/or 11qdel) & \\
No 17p del or 11qdel & & \\
\hline
\end{tabular}

CLL: chronic lymphocytic leukemia, FISH: fluorescence in situ hybridization, del: deletion. 

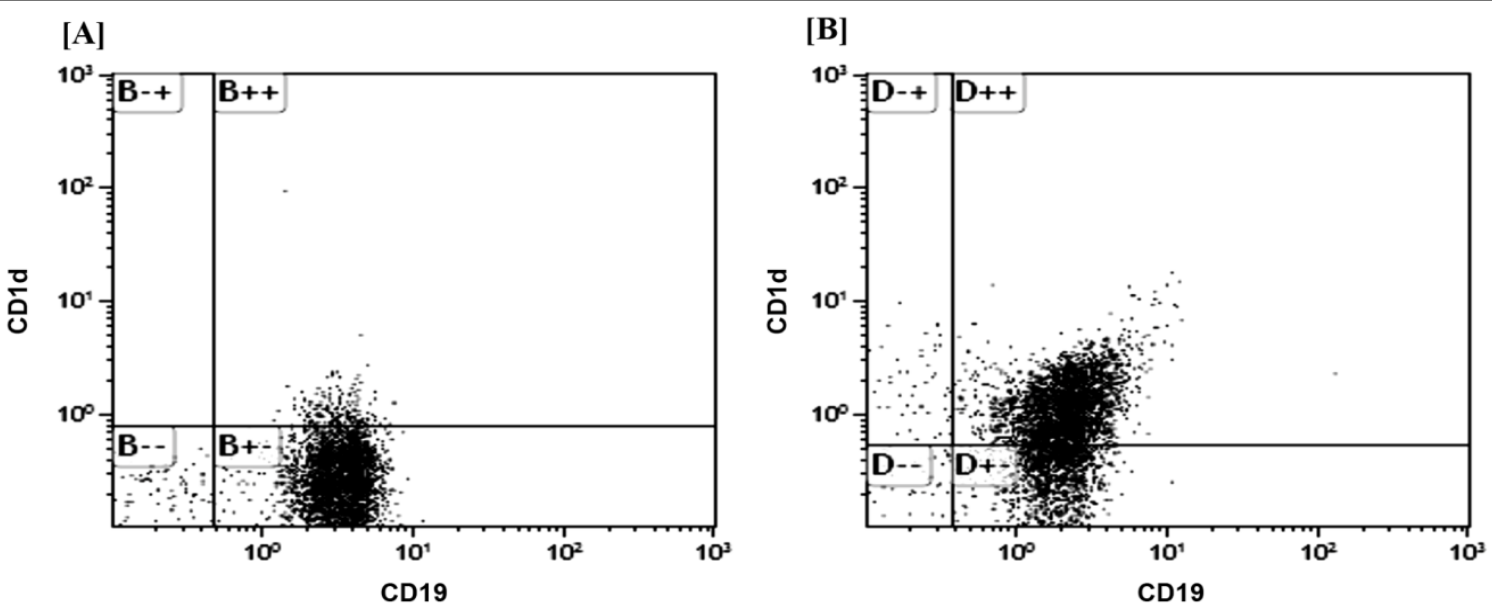

Figure 1. Representative plots of CD 1d expression in [A] A case of chronic lymphocytic leukemia (CLL). [B] A case of mantle cell lymphoma (MCL).

Figure 1. CD 1d expression in [A] CLL [B] MCL
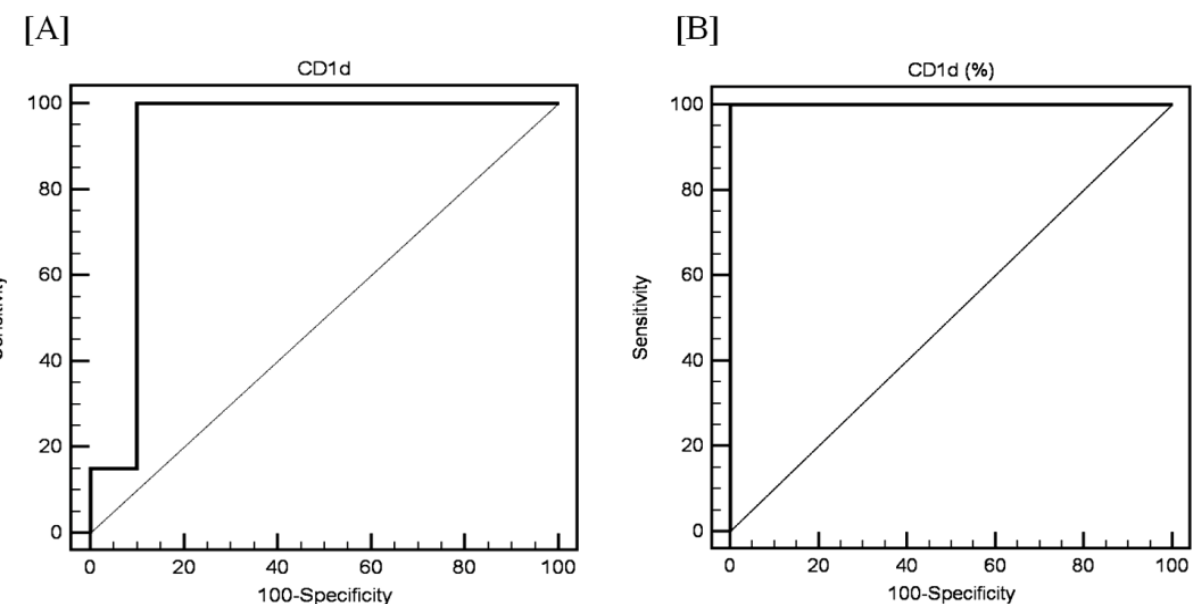

Figure 2. Receiver Operating Curve (ROC) analysis of CD1d as diagnostic marker [A] Chronic lymphocytic leukemia (CLL) compared with mantle cell lymphoma (MCL). [B] CLL compared with CD5 negative B-CLPDs.

Figure 2. Receiver Operating Curve (ROC) analysis of CD1d as diagnostic marker [A] CLL compared with CD5 positive MCL. [B] CLL compared with CD5 negative other B-CLPDs.
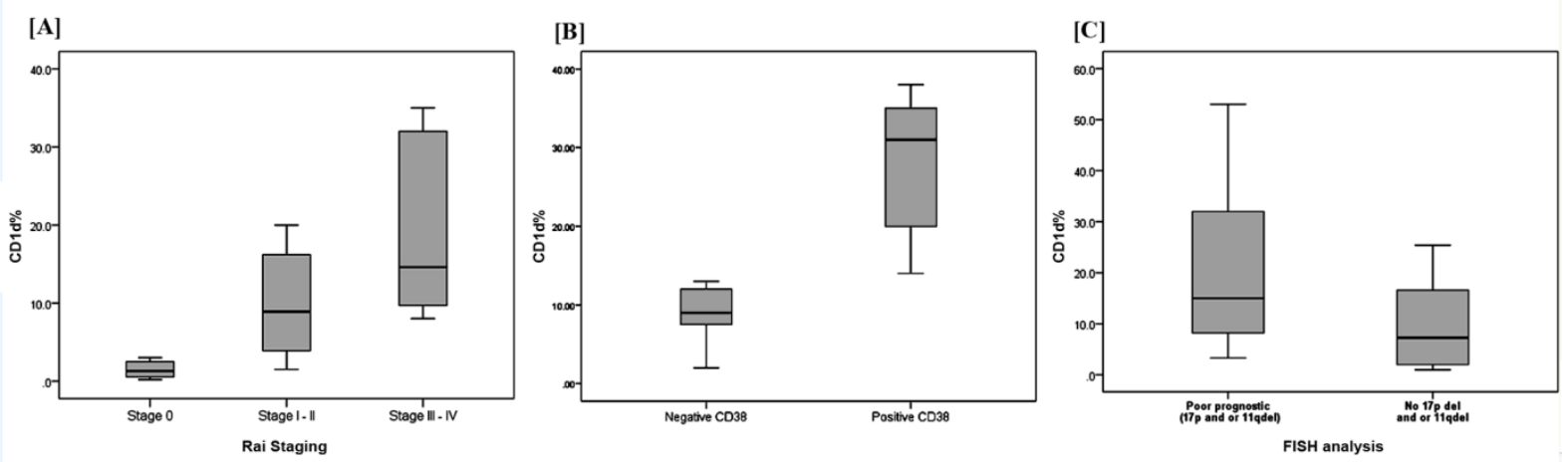

Figure 3. CD1d expression among Different chronic lymphocytic leukemia (CLL) subgroups [A] CLL with different Rai Stages: stage 0, stage I/II, Stage III/IV. [B] CD38 positive and negative CLL patients. [C] CLL patients with poor prognostic cytogenetic aberrations and without cytogenetic abnormalities.

Figure 3. CD1d expression among different CLL subgroups [A] Different Rai Stages; stage 0, stage I/II and stage III/IV. [B] CD38 positive and CD38 negative CLL patients. [C] CLL patients with poor cytogenetic aberrations and without cytogenetic abnormalities. 


\section{Discussion}

CD1d is a MHC class I-like glycoprotein that presents phospholipids and glycolipids to NKT cells. A variety of tumor cell types express CD1d on the surface, particularly those of hematopoietic origin ${ }^{[11]}$. In the present study, the expression of CD1d in CLL cells and other B-CLPDs as well as normal B-lymphocytes has been investigated.

The present study showed lower CD1d expression in CLL patients compared with healthy controls. Consistent with our results Kotsianidis et al. [13] reported higher surface expression of CD1d in healthy controls than in CLL patients. A recent study reported that measuring CD1d by flow cytometer and quantitative reverse transcriptase PCR showed lower CD1d molecule and CD1d mRNA expression in B-cells of CLL patients than of healthy controls ${ }^{[14]}$. Zheng et al. ${ }^{[15]}$ observed a 5-fold reduction of CD1d transcript levels in CLL in comparison with normal B cells by using oligonucleotide microarrays.

Our results demonstrated significantly lower CD1d\% expression virtually restricted to CLL patients compared with MCL and other B-CLPDs. Using ROC curve analysis CD1d cut off value $<38 \%$ was able to diagnose CLL and to differentiate between cases of CLL and MCL with high sensitivity and specificity.

The mechanism of CD1d down-regulation in CLL B-lymphocytes is unknown; however, upregulation of the nuclear protein lymphoid enhancer-binding factor-1 (LEF-1) may be at least partially responsible for the low CD1d expression in CLL ${ }^{[13]}$. It has been demonstrated that the expression of gene encoding the human CD1d (CD1D) is regulated by LEF-1 that acts as a transcriptional repressor of the CD1D gene ${ }^{[16]}$. It was found that LEF-1 is highly expressed in CLL $[17,18,19]$. Moreover, high LEF-1 expression is associated with poor prognosis and disease progression $^{[17]}$.

Finding new prognostic markers for CLL has always been and still is a challenge for investigators. Over the past decade, several prognostic markers of CLL B cells have been added to the original staging systems of Rai and Binet ${ }^{[8]}$. CD38 was the first marker to be discovered and widely used ${ }^{[13,20]}$, high CD38 expression has been identified as an adverse prognostic marker ${ }^{[21]}$. Immunoglobulin heavy chain variable $(\mathrm{IgVH})$ mutational status also confers an adverse prognosis ${ }^{[22]}$, and the presence of chromosomal deletions of $11 \mathrm{q}$ or $17 \mathrm{p}$ are predictive not only of an aggressive clinical course, but also of resistance to specific chemotherapy ${ }^{[23]}$, however, both tests are costly, relatively laborious and not available in all hematology departments ${ }^{[13]}$.

It is interesting that in contrast with the generally low CD1d expression on B lymphocytes in CLL cases, the results of this study showed higher CD1d expression level in CD38 positive CLL cases compared with CD38 negative ones, as well as in CLL patients with advanced disease stages. Previous few studies demonstrated an association between CD1d expression and the adverse immunophenotypic feature, namely CD38 expression in CLL patients ${ }^{[13,24]}$. By contrast, another research group detected no significant differences between Zap-70 positive and negative, CD38 positive and negative CLL sub groups ${ }^{[25]}$. Moreover, higher CD1d expression was detected in CLL patients with the unfavorable cytogenetic abnormalities; 11q23 and/or 17p deletions compared with CLL cases without these cytogenetic abnormalities. Bojarska-Junak et al. ${ }^{[14]}$ demonstrated a significant association of CD1d transcripts, MFI of CD1d or the percentage of $\mathrm{CD}_{1} \mathrm{~d}^{+} / \mathrm{CD} 19^{+}$cells with the stage of disease, as well as, with del (11q22.3) and/or del(17p13.1).

In conclusion, CD1d is a useful diagnostic marker that can be used to differentiate CLL from MCL and other B-CLPDs. Higher CD1d expression in CLL is associated with poor prognosis and can define a subpopulation with more aggressive disease.

Conflicts of interest: nothing to declare. 


\section{Reference}

1. Dronca RS, Jevremovic D, Hanson CA, Rabe KG, Shanafelt TD, Morice WG, Call TG, Kay NE, Collins CS, Schwager SM, Slager SL, Zent CS. CD5-positive chronic B-cell lymphoproliferative disorders Diagnosis and prognosis of a heterogeneous disease entity. Cytometry B Clin Cytom. 2010;78: s35-s41.

2. Zent CS, Kyasa MJ, Evans R, Schichman SA. Chronic lymphocytic leukemia incidence is substantially higher than estimated from tumor registry data. Cancer 2001; 92:1325-1330.

3. Rawstron AC, Bennett FL, Connor SJM, Kwok M, Fenoton JAL, Plummer M, De Tute R, Owen RG, Richards SJ, Jack AS, Hillmen P. Monoclonal B-cell lymphocytosis and chronic lymphocitic Leukemia. N Engl J Med. 2008;359:57583.

4. Jaffe ES. The 2008 WHO classification of lymphomas: implications for clinical practice and translational research. Hematology Am Soc Hematol Edu Program 2009;2009:523-531.

5. Costa ES, Pedreira CE, Barrena S, Lecrevisse Q, Flores J, Quijano S, Almeida J, del Carmen García-Macias M, Bottcher S, Van Dongen JJ, Orfao A. Automated pattern-guided principal component analysis vs expert based immunophenotypic classification of B-cell chronic lymphoproliferative disorders: a step forward in the standardization of clinical immunophenotyping. Leukemia. 2010;24:1927-1933.

6. Morice WG, Kurtin PJ, Hodnefield JM, Shanafelt TD, Hoyer JD, Remstein ED, Hanson CA. Predictive value of blood and bone marrow flow cytometry in B-cell lymphoma classification: comparative analysis of flow cytometry and tissue biopsy in 252 patients. Mayo Clin Proc. 2008;83:776-785.
7. Ho AK, Hill S, Preobrazhensky SN, Miller ME, Chen Z, Bahler DW. Small B-cell neoplasms with typical mantle cell lymphoma immunophenotypes often includes chronic lymphocytic leukemias. Am J Clin Pathol. 2009;131:27-32.

8. Chiorazzi N. Implications of new prognostic markers in chronic lymphocytic leukemia. Hematology Am Soc Hematol Educ Program 2012; 2012:76-87.

9. Cornet E, Debliquis A, Rimelen V, Civic N, Docquier M, Troussard X, Drénou B, Matthes T. Developing Molecular Signatures for Chronic Lymphocytic Leukemia. PLoS ONE 2015;10(6): e0128990. doi:10.1371/ journal.pone.0128990.

10. Liu W, Huber SA. Cross talking between CD 1d restricted NKT cells and YO cells in $\mathrm{T}$ regulatory cell response. Virology jornal.2011;8:32-40.

11. Metelitsa LS. Anti-tumor potential of typeI NKT cells against CD1d-positiveand CD1d-negative tumors in humans. Clin Immunol. 2011;140:119-29.

12. Rai KR, Sawitsky A, Cronkite EP, Chanana AD, Levy RN, Pasternack BS. Clinical staging of chronic lymphocytic leukemia. Blood 1975;46:219-34.

13. Kotsianidis I, Nakou E, Spanoudakis E, Bouchliou I, Moustakidis E, Miltiades P, Vadikolia CM, Szydlo R, Karadimitris A, Tsatalas C. The diagnostic value of CD1d expression in a large cohort of patients withB-cell chronic lymphoproliferative disorders. Am J Clin Pathol 2011;136:400-408.

14. Bojarska-Junak A, Hus I, Chocholska S, Tomczak W, Wos J, Czubak P, Putowski L, Rolinski J. CD1d expression is Higher in chronic lymphocytic leukemia patients with unfavorable prognosis. Leuk Res 2014;38: 435-442.

15. Zheng Z, Venkatapathy S, Rao G. Expression profiling of $\mathrm{B}$ cell chronic 
lymphocytic leukemia suggests deficien CD1-mediated immunity, polarized cytokine response, altere adhesion and increased intracellular protein transport and processing of leukemic cells. Leukemia.2002;16:2429-2437.

16. Chen QY, Zhang T, Pincus SH, Wu S, Ricks D, Liu D, Sun Z, Maclaren N, Lan MS. Human CD1D gene expression is regulated by LEF-1 through distal promoter regulatory elements. J Immunol 2010;184:5047-54.

17. Erdfelder F, Hertweck M, Filipovich A, Uhrmacher S, Kreuzer KA. High lymphoidenhancer-binding factor-1 expression is associated with disease progression and poor prognosis in chronic lymphocytic leukemia. Hematol Rep 2010;2:e3.

18. Gutierrez Jr A, Tschumper RC, Wu X, Shanafelt TD, Eckel-Passow J, Huddleston 3rd PM, Slager SL, Kay NE, Jelinek DF. LEF-1 is a prosurvival factor in chronic lymphocytic leukemiaand is expressed in the preleukemic state of monoclonal B-cell lymphocytosis. Blood 2010;116:2975-83.

19. Howe D, Bromidge T. Variation of LEF-1 mRNA expression in low-grade B-cel lnon-Hodgkin's lymphoma. Leuk Res 2006;30:29-32.

20. Damle RN, Wasil T, Fais F, Ghiotto F, Valetto A, Allen SL, Buchbinder A, Budman D, Dittmar K, Kolitz J, Lichtman SM, Schulman P, Vinciguerra VP, Rai KR, Ferrarini M, Chiorazzi N. IgV gene mutation status and CD38 expression as novel prognostic indicators in chronic lymphocytic leukemia. Blood 1999;94:1840-1847.

21. Rassenti LZ, Jain S, Keating MJ, Wierda WG, Grever MR, Byrd JC, Kay NE, Brown JR, Gribben JG, Neuberg DS, He F, Greaves AW, Rai KR, Kipps TJ. Relative value of ZAP-70, CD38, and immunoglobulin mutation status in predicting aggressive disease in chronic lymphocytic leukemia. Blood 2008;112:192-1930 .

22. Hallek M, Pflug N. State of the art treatment of chronic lymphocytic leukemia. Blood 2011;25:1-9.

23. Morabito F, Cutrona G, Gentile M, Matis S, Todoerti K, Colombo M, Sonaglio C, Fabris S, Reverberi D, Megna M, Spriano M, Lucia E, Rossi E, Callea V, Mazzone C, Festini G, Zupo S, Molica S, Neri A, Ferrarini M. Definition of progression risk based on combinations of cellular and molecular markers in patients with Binet stage A chronic lymphocytic leukaemia. Br J Haematol 2009; 146:44 - 53.

24. Anastasiadis A, Kontsianidis I, Papadopoulos V, Spanoudakis E, Margaritis D, Christoforidou A, Gouliamtzi S, Tsatalas C. CD1d expression as a prognostic marker for chronic lymphocytic leukemia. Leuk Lymphoma 2014;55:320-325.

25. Jadidi-Niaragh F, Tehrani M, Ansaripour B, Razavi SM, Sharifian RA, Shokri F. Reduced frequency of NKTT- like cells in patients with progressive chronic lymphocytic leukemia. Med Oncol 2012;29:3561-3569. 